\title{
The human transmissible spongiform encephalopathies (TSEs): implications for dental practitioners
}

\author{
S. Porter, ${ }^{1}$ C. Scully, ${ }^{2}$ G. L. Ridgway, ${ }^{3}$ and J. Bell, ${ }^{4}$
}

Transmissible spongiform encephalopathies (TSEs) are rare, fatal degenerative brain diseases which affect humans and certain animals, and are caused by inheritance or acquisition of prions (PrPs). Inherited TSEs include Fatal Familial Insomnia (FFI), Gerstmann-Straussler-Scheinker syndrome (GSS) and other less well clinically characterised disorders, while the human infective TSEs include sporadic, iatrogenic and variant Creutzfeldt-Jakob disease (vCJD). The causative prions are found especially in neural tissues and spinal fluid, and in the case of VCJD, in lymphoreticular tissue. Available epidemiological evidence suggests that normal social or routine clinical contact with affected patients does not present a risk to health care workers, relatives or the community. Isolation of patients is not considered necessary. Nevertheless as the prions are resistant to conventional chemical, irradiation and heat sterilisation methods, highly specific cross-infection control measures are required for the dental management of patients with, or at notable risk, of TSE. The present article reviews current knowledge of the clinical consequences of prion disease and provides information regarding necessary changes to the cross-infection routine when managing patients infected, or at risk of, prion disease.

Transmissible spongiform encephalo1 pathies (TSEs) are fatal degenerative prion disorders of humans and certain animals, histopathologically characterised by the appearance of microscopic vacuoles within the grey matter of the brain, giving a sponge-like appearance. There are several

${ }^{1}$ Professor of Oral Medicine, ${ }^{2}$ Dean and Professor of Special Needs Dentistry, Eastman Dental Institute for Oral Health Care Sciences, University College

London, University of London, 256 Gray's Inn Road,

London WC1X 8LD; ${ }^{3}$ Consultant Microbiologist,

${ }^{4}$ Clinical Nurse Specialist, Infection Control,

Department of Clinical Microbiology, University

College London Hospitals, Grafton Way, London

WC1E 6DB

Correspondence to: Professor Stephen Porter,

Department of Oral Medicine, Eastman Dental

Institute for Oral Health Care Sciences, 256 Gray's

Inn Road, London WC1X 8LD

email:S.Porter@eastman.ucl.ac.uk

REFEREED PAPER

Received 17.05.99; accepted 29.11.99

(c) British Dental Journal 2000; 188: 432-436 recognised TSEs, including bovine spongiform encephalopathy (BSE; 'mad cow disease') in cattle, scrapie in sheep and Creutzfeldt-Jakob disease (CJD) in humans. ${ }^{1,2}$

Bovine spongiform encephalopathy (BSE), the first bovine TSE, was described in UK cattle in 1986. An epidemic followed over the next decade, with a peak of new infection in 1988, and clinical cases in $1992 .{ }^{3}$ The cause appeared to be scrapie-infected meat and bone meal in cattle feed. This practice was banned in 1988 and, since there were still new cases, a total ban on the use of all meat and bonemeal for all animal feeds was introduced in 1996. It is also possible that the BSE epidemic stemmed from a change in rendering practices allowing a cattle-specific strain of an infectious agent to contaminate protein supplement, and cause infection. Other potential causes of the BSE epidemic include possible failure to identify an already existing clinical problem of BSE and/or insecticideinduced alteration of prion protein $(\mathrm{PrP}) .{ }^{2} \mathrm{In}$ 1989, TSE appeared in domestic cats in the UK, suggesting transmission of TSE via pet foods, and that the causative agent was not species-specific - confirmed by the appearance of TSEs in many captive animal species (eg Arabian oryx, scimitar horned oryx, greater kudu, eland, puma, cheetah, ocelot and tiger). ${ }^{2,4}$ Subsequent to the BSE epidemic, a variant of sporadic CJD was observed in humans in 1996, and later found to be associated with the consumption of infected bovine offal. ${ }^{1,2}$

Prion-induced disease - underlying pathology

The TSEs are caused by prions (Proteinaceous infectious particle), abnormal isoforms of a cell surface glycoprotein designated PrP. ${ }^{5}$ The prions resist inactivation by processes that modify nucleic acids, and accumulate in brain tissue, sometimes forming amyloid-like deposits. It is now possible to strain type the different prions based upon animal innoculation studies and/or western blot

In brief

- Transmissible spongiform encephalopathies (TSEs) are rare brain diseases affecting humans and certain animals.

- Prions are the cause of these infections, being particularly found in neural tissues, spinal fluids, and in some instances lymphoreticular tissues.

- Variant Creutzfeldt-Jakob disease (vCJD) gives rise to degenerative disease. Although very uncommon, vCJD has occurred in young adults in the UK and other parts of Europe.

- There is no evidence that dental healthcare workers are at risk of acquisition of infective prions in routine dental care.

- In view of the difficulty of inactivating prions, all patients infected, or likely to be infected, with prions should be treated in a hospital-based clinic. 
analysis. The prion associated with BSE and variant CJD is similar. ${ }^{2,6-8}$ In man, the normal prion protein ( $\mathrm{PrP}$ (protease-resistant protein)) is encoded by a single-copy host PrP gene on chromosome 20.9,10 The normal product of the prion protein gene $(\mathrm{PRnP})$ is soluble and protease sensitive (PrPsens or PrPC), and not harmful, however in the inherited TSEs there is a coding mutation in the PRNP giving rise to an abnormal PrP protein that is insoluble and insensitive to proteases (PrPres or PrPSc), and lethal to neural tissue. ${ }^{10-12}$ The infective disorders such as vCJD and iatrogenic CJD arise because of the acquisition of abnormal PrP which catalyses the generation of more defective PrP within host cells, hence inducing disease. ${ }^{2}$

\section{Human transmissible spongiform encephalopathies}

The human TSEs, or prion diseases, occur in inherited, acquired or sporadic forms. The inherited forms are all autosomal dominant disorders that do not manifest until early to middle adult life. ${ }^{13}$ The acquired human prion diseases include sporadic, iatrogenic and variant CJD. The majority of acquired CJD is caused by randomly occurring sporadic CJD. This form of CJD has been observed worldwide with an incidence of about 1 per million population, and arises in middle to late life. ${ }^{14}$ Variant CJD (vCJD) is rare - around 50 people have been seen to be affected - but is geographically located in Europe and almost all affected individuals have been UK teenagers or young adults. ${ }^{15}$

\section{The inherited human TSEs}

There are several inherited TSEs, all are autosomal dominant and include families with individual mutations and those with disorders that may be clinically defined, for example Fatal Familial Insomnia (FFI) and Gerstmann-Straussler-Scheinker syndrome (GSS). ${ }^{13}$

\section{Fatal familial insomnia}

Fatal Familial Insomnia (FFI) is clinically characterised by progressive insomnia, dysautonomia, disruption of circadian rhythms, motor dysfunction and variable deterioration in cognition. ${ }^{10}$ The usual age of onset is between 40 and 60 years, and the course of illness lasts between 7 and 18 months. Affected families have been reported in several parts of the world. There is deposition of modified amyloid protein and neuronal depletion particularly within the anteroventral and mediodorsal thalamic nuclei. Polymorphism of codon 129 of the PRNP determines clinical presentation, hence within affected families disease can present like FFI or CJD. ${ }^{16-20}$

\section{Gerstmann-Straussler-Scheinker syndrome}

In Gerstmann-Straussler-Scheinker syndrome (GSS) there are a variety of mutations within PRNP different to those of FFI. Families from around the world have been reported to be affected. Clinical features of GSS include profound chronic cerebellar ataxia, pyramidal features and slow onset dementia. The usual age of onset is 20 to 30 years, and the clinical course is about 5 years - much longer than any CJD. ${ }^{21,22}$

\section{Other familial human prion diseases}

There are occasional families in which there is autosomal-dominant inherited prion disease. These families have genetic defects different to those of FFI and GSS, but affected individuals still die from CJD-like illness. ${ }^{23,24}$

\section{Acquired human TSEs \\ Kuru}

Kuru is an acquired spongiform encephalopathy first described in the 1950s which, although in decline, was the first recognised human transmissible prion disease. ${ }^{25}$ Affected individuals all came from Papua New Guinea, tended to be young adults and acquired infection as a consequence of cannibalistic rituals. Women and children were particularly liable as they prepared the tissues and ate the viscera. Typically there was progressive cerebellar ataxia but, unlike CJD, dementia was not a common or predominant clinical feature. While cannibalism ceased in the 1950s, there are still occasional new instances of kuru in patients more than 40 years of age, perhaps suggesting a long incubation time. ${ }^{25,26}$

\section{Sporadic Creutzfeldt-Jakob disease}

Sporadic CJD is a rapidly progressive multifocal dementia accounting for the majority of human TSEs world-wide. It typically arises in middle to late life, with a peak age of onset between 60 and 65 years of age. ${ }^{14}$ There is rapid progression, over weeks, to an akinetic mutism. Aside from the predominant mental deterioration and myoclonus, there can be extrapyramidal and pyramidal signs, cerebellar ataxia and cortical blindness. Up to a third of patients may have prodromal symptoms that include insomnia, fatigue, depression, weight loss, headache, general malaise and ill-defined pain. ${ }^{26}$

The only useful specific investigation of sporadic CJD is electroencephalography (EEG), which shows characteristic changes. There are no amyloid plaques in affected brain tissue, although there is spongiform change, neuronal loss and astrocytosis, although spongiform change is a late feature. The causative prion is not present in lymphoid tissue. ${ }^{27,28}$

latrogenic Creutzfeldt-Jakob disease CJD-like disease has arisen following prion transmission via cadaver-derived growth hormone, pituitary gonadotropins, dura mater homografting, corneal grafts or inadequately sterilised intracerebral surgical equipment. ${ }^{29-34}$ Iatrogenic CJD varies clinically from a sporadic-CJD type disease to a more slow-onset disease reminiscent of kuru. The causative prion does not occur in lymphoid tissue.

\section{Variant Creutzfeldt-Jakob disease}

Variant CJD (vCJD) is localised to Europe, particularly the UK, and has almost always affected teenagers or young adults, the mean age of onset being 24 years. ${ }^{35-37}$

Unlike sporadic or iatrogenic CJD, vCJD typically presents with severe depression or other mental illness, and/or sensory disturbances (dysaesthesia or paraesthesia). These symptoms last several months and are followed by dementia, cerebellar and other neurological signs, myoclonus or other involuntary movements, and finally akinetic mutism..$^{38,39}$ The clinical course of the variant disease is much longer than that of sporadic CJD and affected patients do not have the typi- 
cal EEG changes of the latter disorder. In contrast to sporadic CJD there is extensive plaque deposition in brain tissue of vCJD patients. Of note, prions can be demonstrated in lymphoid tissue of the affected patients. ${ }^{40}$

\section{Oral manifestations of human TSEs}

Oral manifestations of human TSEs comprise dysphagia and dysarthia (due to pseudobulbar palsy), and in vCJD patients there may be orofacial dysaesthesia or paraesthesia. $^{38,39}$

\section{Relevant aspects of infection control}

The causative prions of sporadic and iatrogenic CJD are typically located to the brain and spinal tissues. Of particular concern, and in contrast to other human infective prion disorders, the causative prion of VCJD is present in lymphoid tissue (eg pharyngeal tonsil, lymph nodes and spleen). ${ }^{40}$ The vCJD PrP occurs within CD35+CD21+ follicular dendritic cells (not $\mathrm{T}$ or B cells), within all sites of the body. ${ }^{40}$ While it has yet to be demonstrated, it is likely that the PrP will be present within lingual tonsillar tissue (J. Collinge, personal communication).

It is unclear as yet why lymphoid tissue of variant CJD is so infected with $\mathrm{PrP}$ as opposed to the other human TSEs, but lymphoreticular involvement also occurs in scrapie and BSE. It may be that there is lymphoreticular invasion before neural involvement, as PrP was found in the appendix of a patient 8 months before onset of neurological vCJD,${ }^{41}$ and in BSE and scrapie there is early infection of the gut lymphoreticular system. ${ }^{42-44}$ The dendritic cells may be a site of prion replication, white B lymphocytes may be important in the transport of prions. ${ }^{45}$ To date there is no evidence that blood or blood products are likely routes of spread of any human CJD-like illness but as vCJD PrP is in lymphoreticular tissue (even if not in peripheral blood cells within tissue) and B lymphocytes may have a role in the pathogenesis of such disease, it is not possible to exclude completely the rare possibility of PrP of vCJD being present in the blood. Of concern, blood from a patient with GSS did give rise to infection in mice, infectivity occurring in the plasma, leucocytes, cryoprecipitate and in fraction I+II-III. ${ }^{46}$

\begin{tabular}{|c|c|c|}
\hline Table 1 & \multicolumn{2}{|c|}{$\begin{array}{l}\text { Identification of patients with, suspected of, or at-risk of } \\
\text { CJD-like disease I }\end{array}$} \\
\hline \multicolumn{2}{|c|}{ Known or suspect patients } & At-risk patients \\
\hline \multicolumn{2}{|c|}{$\begin{array}{l}\text { Patients diagnosed as having CJD or a } \\
\text { related disorder* }\end{array}$} & $\begin{array}{l}\text { Asymptomatic patients who are } \\
\text { potentially at risk of developing CJD or } \\
\text { a related disorder* }\end{array}$ \\
\hline \multicolumn{2}{|c|}{$\begin{array}{l}\text { Patients suspected of having CJD or a } \\
\text { related disorder* ie have clinical } \\
\text { symptoms that are suggestive of CJD but } \\
\text { where the diagnosis has not yet been } \\
\text { confirmed }\end{array}$} & $\begin{array}{l}\text { Recipients of hormone derived from } \\
\text { human pituitary glands, eg growth } \\
\text { hormone, gonadotrophin (but not those } \\
\text { given only recombinant hormone) } \\
\text { Recipients of human dura mater grafts; } \\
\text { People with a family history of familial } \\
\text { CJD, ie close blood line relatives } \\
\text { (parents, brothers, sisters, children, } \\
\text { grandparents and grandchildren of FFI, } \\
\text { GSS and familial CJD). }\end{array}$ \\
\hline
\end{tabular}

Patients with the human TSEs are infectious. Disease is likely however to be spread only by blood or tissue contact with infected material - particularly brain, spinal and perhaps lymphoidal tissue. Nevertheless, as prions are not inactivated by conventional disinfection, irradiation or heat sterilisation particular precautions have to be taken with all affected patients, and those potentially infected or at-risk of infection with prions. ${ }^{2}$

There is no evidence to suggest that dental healthcare staff are at any risk of occupational exposure of prion disease, although scrapie may be transmitted via pulpal tissue in hamster models. ${ }^{47}$ In view of the potential for iatrogenic spread, and the difficulties of inactivating prions, a number of aspects of the cross-infection control regime ${ }^{48}$ require to be modified. Normal standards of dental hygiene, such as eye protection, masks and gloves should be supplemented by the following recommendations.

\section{Patients at risk of prion disease}

It is essential to distinguish between patients who are known or suspected to have CJD or a related disorder (ie symptomatic) and those who are potentially at risk of developing one of these diseases, but presently asymptomatic. ${ }^{1}$

In particular, those persons with a history of familial CJD, such as a parent or other close blood relative who is thought to have, or have had, GSS, FFI or another familial CJD are potentially at risk of prion carriage. Parents of patients with vCJD, and household members of sporadic or iatrogenic CJD are however not regarded as at risk (Table 1). ${ }^{1}$ Likewise, patients with other dementias (eg Alzheimer's) are not at-risk of prion disease.

\section{Dental health care clinical procedures}

The clinical care of patients with, suspected of having, or at-risk of CJD, should be undertaken by the minimum number of healthcare staff needed to ensure effective treatment. All treatment should be carefully planned in advance. In view of the difficulties of using dental handpieces and sterilisation procedures, such patients should be treated at the end of a clinical session by a skilled clinical team

\section{Dental Instruments}

Equipment used in patients with known CJD

All dental equipment used in the management of a patient with known CJD etc must be destroyed after use - hence wherever possible single-use disposable instruments are required.

Equipment used in patients at-risk of CJD If the procedure involves brain, spinal cord or eye tissue the instruments will require to be destroyed, hence single-use equipment should be used.

If these tissues are not touched as is the case in all routine dental care, conventional instruments can be used, BUT they MUST be sterilised under very stringent conditions (see Table 2).

\section{Equipment used in patients with} suspected CJD

Non-single use instruments must be quarantined after use in a rigid leak-proof sealed plastic container until the exact status of the patient is determined. If the patient is found to have CJD etc, or the diagnosis remains possible, the instruments must be destroyed. If CJD is proven not to be present the instruments can be reprocessed in a conventional manner.

Surgical instruments (if incineration is not required) should be put through the standard hospital procedures for re-processing instruments on release from quar- 


\section{Table 2 Recommended methods of inectivation of human TSE agents \\ - 20,000 ppm available chlorine of sodium hypochlorite for 1 hour \\ - $2 \mathrm{M}$ sodium hydroxide for 1 hour \\ - Non-porous load steam steriliser $134-137^{\circ} \mathrm{C}$ for a single cycle of 18 minutes, or six successive cycles of 3 minutes each* \\ * but known not to be completely effective}

antine, ie cleaned, inspected, function tested, packed and sterilised, before being made available for use on another patient.

\section{Dental handpieces}

The handpiece must NOT be connected to the waterline of the dental unit as there is a remote chance of clinical material being sucked into the waterlines, and these are very unlikely to withstand the recommended method of chemical inactivation of prions. Water for cooling of the tissues must be provided from a separate source (eg infusion or syringe). If the patient has CJD or is liable to CJD, the handpiece must be discarded after use. If the patient is only at-risk of CJD, the handpiece may be heat-sterilised under the conditions outlined in Table 2.

\section{Suction}

In view of the difficulties of disinfection the suction system of the dental unit cannot be used; instead a stand-alone suction unit is required. The reservoir of the suction unit should be disposable. The spittoon of the dental unit should not be used, instead patients should expectorate into a disposable bowl, and this should be discarded directly into the clinical waste bin for incineration.

\footnotetext{
Labelling and transportation of instruments

All instruments and items of equipment that have been in contact with known, suspect or at risk patients must be clearly identified. Items used on patients known or suspected of being prion-infected should be labelled for disposal. Items used on at-risk patients, where there has been contact with brain, spinal cord or eye, should also be labelled for disposal, while those used on other tissues should be labelled either for re-processing or disposal as appropriate.
}

Items for re-processing should be securely contained in a robust, leak-proof container, and transferred by a designated person to the sterilisation services department.

Items for disposal by incineration should be isolated in a rigid leak-proof combustible clinical waste container and transported to the incinerator as soon as practicable, in line with the current disposal of clinical waste guidance.

\section{Percutaneous exposure to patient tissue/fluids}

Sharps injuries involving blood or saliva from patients with or at-risk of CJD should be managed like any other similar incident. The injured site should be encouraged to bleed, gently washed with warm soapy water, rinsed, dried and covered with a waterproof dressing, or further treatment given appropriate to the type of injury.

Splashes into the eye or mouth should be dealt with by thorough irrigation. All accidents should be appropriately reported and recorded.

\section{Spillages}

Spillage of potentially CJD-infectious materials should be removed using absorbent material, the surface disinfected with an appropriate disinfectant (see Table 2) and any waste disposed of as clinical waste by incineration. Disposable gloves and an apron should be worn when removing such spillages and disposed of by incineration.

\section{Biopsy samples}

Biopsy samples from known, suspect or atrisk patients should only be taken by experienced clinicians who are aware of the hazards involved. Samples should be marked with a 'Biohazard' label and particular consideration should be given to the need to maintain patient confidentiality, however the pathology laboratory must be notified specifically of any risk.

\section{Cleaning, decontamination and waste disposal}

As discussed previously, prions are highly resistant to standard physical and chemical methods of inactivation and decontamination. The standard autoclave regimen is ineffective. Gases such as ethylene oxide and formaldehyde are ineffective, as are most chemical disinfectants such as alcohols, formalin, aldehydes (eg glutaraldehyde), beta propiolactone, hydrogen peroxide, iodophors, peracetic acid and phenolics.

Sodium hypochlorite has been shown to be effective but only at very high concentration, while sodium hydroxide does not cause complete inactivation. Ionising or UV irradiation at conventional doses and dry heat are also not effective.

\section{Maxillofacial surgery affecting the brain or eyes of patients with, or at-risk of CJD}

Invasive procedures of the eyes or brain (eg after profound facial injury) of patients with, or at-risk of CJD, necessitates using disposable instruments as much as possible, and destroying all other instruments. Expensive items of equipment, such as drills, may be prevented from being contaminated by using shields, guards or coverings, so that the entire items do not need to be destroyed. The drill bit, bur, other parts in contact with high risk tissue, and the protective coverings must be incinerated. However, in practice, it may be difficult to ensure effective protective covering, and advice should be sought from the manufacturer to determine practicality. Wherever possible the patient should be last on the day's operating list. No other discrimination should be permitted.

There is no evidence to suggest that patients who received dura mater allografts for the management of maxillofacial defects have developed iatrogenic CJD. However, such procedures should no longer be undertaken. 


\section{Staff training}

All staff directly involved in procedures on patients in the risk groups, or in the subsequent re-processing or disposal of potentially contaminated items, should be aware of the specific precautions, and adequately trained.

\section{Dental healthcare staff potentially infected with prions}

It is advisable that dental healthcare staff potentially with prion disease should not practice invasive clinical procedures in view of the risk of motor and cognitive dysfunction. Nevertheless, at the time of writing, the General Dental Council has not produced guidelines.

1 Advisory Committee on Dangerous Pathogens Spongiform Encephalopathy Advisory Committee. Transmissible spongiform encephalopathy agents: safe working and the prevention of infection. The Stationery Office 1998; pp1-54.

2 Patterson W J, Painter M J. Bovine spongiform encephalopathy and new variant CreutzfeldtJakob disease: an overview. Communicable Dis Public Health 1999; 2: 5-13.

3 Anderson R M, Donnelly C A, Ferguson N M, Woolhouse M E J, Watt C J, Udy H J et al. Transmission dynamics and epidemiology of BSE in British cattle. Nature 1996; 382: 779-88.

4 Kirkwood J K, Cunningham A A. Epidemiological observations on spongiform encephalopathies in captive wild animals in the British Isles. Vet Rec 1994; 135: 296-303.

5 Prusiner S B. Natural and experimental prion disease of humans and animals. Curr Opin Neurobiol 1992; 2: 63847.

6 Bruce M, Chree A, McConnell I, Foster J, Pearson G, Fraser H. Transmission of bovine spongiform encephalopathy and scrapie to mice: strain variation and the species barrier. Philos Trans R Soc Lond Biol Sci 1994: 343: 405-411.

7 Bruce M E, Will R G, Ironside J W, McConnell I, Drummond D, Suittie A et al. Transmissions to mice indicate that 'new variant' CJD is caused by the BSE agent. Nature 1997; 389: 498-501.

8 Collinge J, Sidle K C L, Meads J, Ironside J, Hill, A F. Molecular analysis of prion strain variation and the aetiology of 'new variant' CJD. Nature 1996; 383: 685-690.

9 Prusiner S B. Prion encephalopathies of animals and humans. Dev Biol Stand 1993; 80: 31-44.

10 Goldman W. PrP gene and its association with spongiform encephalopathies. Br Med Bull 1993; 49: 839-859.

11 Merz P A, Somerville R A, Wisniewski H M, Manuelidis L, Manuelidis E E. Scrapieassociated fibrils in Creutzfeldt-Jakob disease. Nature 1983; 306: 474-476.

12 Taylor D M. Inactivation of the unconventional agents of scrapie, bone spongiform encephalopathy and Creutzfeldt-Jakob disease. J Hosp Infect 1991; 18 (Suppl A): 141-146.

13 Collinge J. Prion Diseases. In Weatherall D J, Ledingham J G G, Warrell D A (eds). Oxford Textbook of Medicine. 3rd Edition. Oxford: Oxford University Press 1996; pp3977-3983.

14 Cousens S N, Zeidler M, Esmonde T F, De Silva R, Wilesmith J W, Smith P G et al. Sporadic Creutzfeldt-Jakob disease in the United Kingdom: analysis of epidemiological surveillance data for 1970-96. BMJ 1997; 315: 389-396.

15 Cousens S N, Linsell L, Smith P G, Chandrakumar M, Wilesmith J W, Knight, RSG et al. Geographical distribution of variant CJD in the UK (excluding Northern Ireland). Lancet 1999; 353: 18-21.

16 Montagna P, Cortelli P, Avoni P, Tinuper P, Plazzi G, Gallassi R, et al. Clinical features of fatal familial insomnia: phenotypic variability in relation to a polymorphism at codon 129 of the prion protein gene. Brain Pathol 1998; 8: 515-520.

17 McLean C A, Storey E, Gardner R J, Tannenberg A E, Cervenakova L, Brown P. The 'fatal familial insomnia' mutation associated with diverse clinicopathologic phenotypes in an Australian kindred. Neurol 1997; 49: 552-558.

18 Fiorino A S. Sleep, genes and death: fatal familial insomnia. Brain Res 1996; 22: 258-264.

19 Gallassi R, Morreale A, Montagna P, Cortelli P, Avoni P, Castellani R et al. Fatal familial insomnia: behavioural and cognitive features. Neurol 1996; 46: 935-939.

20 Parchi P, Castellani R, Cortelli P, Montagna P, Chen, SG, Petersen, RB, Manetto, V, VnencakJones C L, McLean M J, Sheller J R et al. Regional distribution of protease-resistant prion protein in fatal familial insomnia. Ann Neurol 1995; 38: 21-219.

21 Prusiner, S B. The prion diseases. Brain Pathol 1998; 8: 499-513.

22 Weber T, Aguzzi A. The spectrum of transmissible spongiform encephalopathies. Intervirology 1997; 40: 198-212.

23 Ironside J W. Human prion diseases. J Neur Trans 1996; 47: 231-246.

24 Prusiner S B. Molecular biology and pathogenesis of prion diseases. Trends in Biochem Sci 1996; 21: 482-487.

25 Zigas V. Kuru: a critical review. Med J Aust 1975; 2: 483-486.

26 Collinge J, Palmer M S. Prion diseases. Oxford: Oxford University Press, 1997, pp30-32.

27 Lantos P L. From slow virus to prion protein: a review of transmissible spongiform encephalopathies. Histopathology 1992; 20: 1-11.

28 Collinge J, Owen F, Poulter M, Leach M, Crow $\mathrm{T}$ J, Rossor M N et al. Prion dementia without characteristic pathology. Lancet 1990; 336: 7-9.

29 Healy D L, Evans J. Creutzfeldt-Jakob disease after pituitary gonadorophins. BMJ 1993; 307: 517-518.

30 Buchanan C R, Preece M A, Milner R D. Mortality, neoplasia, and Creutzfeldt-Jakob disease in patients treated with human pituitary growth hormone in the United Kingdom. BMJ 1991; 302: 824-828.

31 Allan B, Tuft S. Transmission of Creutzfeldt-
Jakob disease in corneal grafts. BMJ 1997; 315: 1553-1554.

32 Yamada M, Itoh Y, Suematsu N, Matsushita M, Otomo E. Panencepalopathic type of Creutzfeldt-Jakob disease associated with cadaveric dura mater graft. J Neurol Neurosurg Psychiatry 1997; 63: 524-527.

33 Clavel M, Clavel P. Creutzfeldt-Jakob disease transmitted by dura mater graft. Euro Neurol 1996; 36: 239-240.

34 Collins S J, Masters C L. Transmissibility of Creutzfeldt-Jakob disease and related disorders. Sci Progress 1995; 78: 217-227.

35 Will R G, Ironside J W, Zeidler M, Cousens S N Estibeiro K, Alperovitch A et al. A new variant of Creutzfeldt-Jakob disease in the UK. Lancet 1996; 347: 921-925.

36 Brown P. Bovine spongiform encephalopathy and Creutzfeldt-Jakob disease. BMJ 1996; 312: 790-791.

37 Deslys J P, Lasmezas C I, Streichenberger N, Hill A, Collinge J, Dormont D et al. New variant Creutzfeldt-Jakob disease in France. Lancet 1997; 349: 30-31.

38 Zeidler M, Johnstone E C, Bamber R W, Dickens C M, Fisher C J, Francis A F et al. New variant Creutzfeldt-Jakob disease: psychiatric features. Lancet 1997; 350: 908-910.

39 Zeidler M, Stewart G E, Barraclough C R, Bateman D E, Bates D, Burn D J et al. New variant Creutzfeldt-Jakob disease: neurological features and diagnostic tests. Lancet 1997; 350: 903-907.

40 Hill A F, Butterworth R J, Joiner S, Jackson G, Rossor M N, Thomas D J et al. Investigation of variant Creutzfeldt-Jakob disease and other human prion diseases with tonsil biopsy samples. Lancet 1999; 353: 183-189.

41 Hilton D A, Fathers E, Edwards P, Ironside J W, Zajicek J. Prion immunoreactivity in appendix before clinical onset of variant CreutzfeldtJakob disease. Lancet 1998; 352: 703-704.

42 Wells G A, Dawson M, Hawkins S A et al. Infectivity in the ileum of cattle challenged orally with bovine spongiform encephalopathy. Vet Rec 1994; 135: 40-41.

43 Hadlow W J, Kennedy R C, Race R E. Natural infection of Suffolk sheep with Scrapies virus. $J$ Infect Dis 1982; 146: 657-664.

44 Schreuder B E C, van Keulen L J M, Vromans, M E W, Langeveld J P M, Smits M A. Preclinical test for prion diseases. Nature 1996; 381: 563.

45 Klein M A, Frigg R, Flechsig E, Raeber A J, Kalinke U, Bluethmann $\mathrm{H}$ et al. A crucial role for B cells in neuroinvasive scrapie. Nature 1997; 390: 687-690.

46 Brown P, Rohwer R G, Dunstan B C, MacAuley C, Gajdusek D C, Drohan W N. The distribution of infectivity in blood components and plasma derivatives in experimental models of transmissible spongiform encephalopathy. Transfusion 1998; 38: 810-816.

47 Ingrosso L, Pisani F, Pocchiari M. Transmission of the $263 \mathrm{~K}$ scrapie strain by the dental route. $J$ Gen Virol 1999; 80: 3043-3047.

48 British Dental Association. Advice Sheet A12: Infection Control in Dentistry. www.bdadentistry.org.uk. 2000 